\title{
Elevated DKK1
}

National Cancer Institute

\section{Source}

National Cancer Institute. Elevated DKK1. NCI Thesaurus. Code C157584.

A finding indicating elevated concentrations of DKK1 in a sample. 